\title{
Del insomnio provocado por el hay, al despertar ético del rostro: tras las huellas de la vigilancia levinasiana como actitud crítica y autocrítica gracias a la epojé
}

\section{(On the insomnia provoked by the there is, at the ethical awakening of the face of the Other: following the footsteps of the levinasian vigilance as a critical and autocritical notion derived from de epojé)}

\author{
Francisco IDARETA GOLDARACENA
}

Recibido: 9 de junio de 2011

Aceptado: 20 de diciembre de 2011

\section{Resumen}

Nuestro objetivo consiste en trasladar que, desde la perspectiva levinasiana, la noción de hay resulta ser el antecesor conceptual del rostro del Otro y que la vigilancia extrema a la que somos despertados consiste fundamentalmente en aquella actitud crítica y autocrítica descategorizante a la que la vulnerabilidad del Otro nos exige tras haber sentido prevoluntariamente su irreductibilidad. Conjeturamos que esta actitud crítica y autocrítica se corresponde con la epojé y posibilita remontar todo proceso ontológico a su estado preoriginario irreductible.

Palabras clave: hay, rostro, epojé, vigilancia, crítica, E. Lévinas

\begin{abstract}
Our objective consists of proposing that the concept of -from the levinasian perspective- the there is is ultimately the conceptual predecessor of the face of the Other, and that the extreme vigilance to which we awaken fundamentally consists
\end{abstract}


of that decategorization of the critical and autocritical notion to which the vulnerability of the Other forces us to succumb to after having prevoluntarily felt its irreducibility. We speculate that this critical and auto-critical notion corresponds to the concept of the epojé, and therefore it permits to take all ontological processes back to their irreducible preoriginary state.

Keywords: There is, Face of the Other, Epojé, Vigilance, E. Levinas.

\section{Introducción}

La fidelidad de Emmanuel Lévinas a su propuesta ética inicial resulta sorprendente. Pese a las comprensibles transformaciones que se han ido produciendo a lo largo de su obra, lo cierto es que la propuesta ética levinasiana ya se encontraba parcialmente esbozada en sus primeras obras. La crítica de Jacques Derrida fue crucial para la evolución del pensamiento levinasiano, aunque únicamente en lo que respecta a la forma, puesto que el contenido se encuentra condensado ya en sus primeros escritos. La fidelidad de Lévinas al método fenomenológico es otra constante en su obra. Un método del que hará un uso particular, utilizando la epojé, que consiste en remontar lo tematizado a su estado anterior, en devolver a su estado originario lo categorizado.

Consideramos que, desde sus primeras obras, la epojé ha posibilitado a Lévinas el desarrollo de nociones como el hay, el rostro, la sensibilidad y la vigilancia. De hecho, consideramos que la vigilancia a la que alude Lévinas en sus primeras obras es una transmutación de la epojé, puesto que consiste en devolver lo categorizado a su estado preoriginario descategorizándolo; en aquella actitud crítica y autocrítica para con nuestro proceder ontológico por exigencia de una sensibilidad preoriginaria a la que hemos sido despertados por el rostro del Otro. Una actitud crítica y autocrítica que será la que nos posibilite la adquisición de un conocimiento ético que instaure nuestra tolerancia y deferencia para con el Otro, al que, en adelante, nos privaremos de ajustar definitivamente a la medida de nuestras categorías cognitivas.

Por todo ello, planteamos dos conjeturas: que la noción de hay es el antecesor conceptual de la importantísima noción de rostro en la propuesta ética levinasiana; así como que, la vigilancia que instaura la intrusión del rostro en el sujeto ético se produce gracias a la epojé como actitud crítica y autocrítica que vela por descategorizar lo ontológicamente categorizado. En sus primeras obras, el hay provocaba nuestro insominio: algo que resultaba incontrolable para nuestra voluntad, nos impedía dormir. Más adelante, gracias al método fenomenológico o epojé, Lévinas concebirá que será el rostro, más allá de la cara, más allá de la fachada fenomenal, el que nos mantiene insomnes, vigilantes, debido a la vulnerabilidad que éste expre- 
sa y que provoca la mía propia, a modo de responsabilidad para con él, instaurando así mi alerta permanente que impide categorice definitivamente al Otro. Nos hemos planteado tales conjeturas a partir del pormenorizado análisis crítico de nuestra propia aportación1. Una aportación que cabría integrar dentro del escaso surtido de intentos de aproximar a diferentes disciplinas la propuesta ética de Lévinas ${ }^{2}$.

Así, con el propósito de trasladar todo esto, en la primera parte, realizaremos un breve recorrido a través de su vida y obra, donde señalaremos la importancia de las tradiciones griega y hebrea en la elaboración de nociones como el rostro, la sensibilidad, la vigilancia y la epojé. En la segunda parte, describiremos las nociones de hay y de rostro, ambas vinculadas al insominio, a la alerta, a la vigilancia del sujeto que lo padece a su pesar, de forma pasiva, antes de poderlo elegir. En la tercera parte, señalaremos las similitudes y diferencias entre las nociones de hay y de rostro. En la cuarta parte, plantearemos el hay como antecesor conceptual de la noción del rostro. En la quinta parte, describiremos la noción de epojé como método que posibilita a Lévinas ir siempre más allá de la propia fenomenología. En una sexta parte, plantearemos la epojé como antecesor conceptual de la noción de vigilancia. Una epojé que, en la séptima y última parte, la presentamos como esa actitud crítica y autocrítica que es instaurada en el sujeto ético por la impactación que padece tras la intrusión de la imprevisible e inmediata vulnerabilidad del rostro sufriente del Otro.

\section{Vida y obra de E. Lévinas: el despertar ético al rostro del otro a partir de las tradiciones griega y hebrea}

Consideramos que Lévinas es uno de los filósofos más importantes del siglo $\mathrm{XX}$, reconocido principalmente por la radicalidad de su crítica a la filosofía occidental. Destacaremos dos acontecimientos vitales que marcaron profundamente su obra: haber sido alumno de Husserl y Heidegger y su estancia como prisionero en un campo de trabajo nazi. Con respecto a su obra, Lévinas escribe obras filosóficas y confesionales. De hecho, es por ello que cuenta con dos editores distintos. En nuestro caso, nos basamos principalmente en las dos obras filosóficas que consideramos son las más importantes de toda su aportación: Totalidad e Infinito (1961) y De otro modo que ser o más allá de la esencia (1974). En cuanto a las características de su obra, destacamos que la filosofía manifiesta de Lévinas se sustenta sobre

\footnotetext{
1 Cfr. Idareta (2010b).

2 Al Trabajo Social -Cfr. Rossiter (2011); Rubilar (2009)-, a la Pedagogía -Cfr. Baptista (2006)-, a la Enfermería -Cfr. Galvin \& Todres (2009); Helin \& Lindström (2003); Watson (2003); Nortvedt (2001)-, a la Medicina -Cfr. Belli \& Quadrelli (2010); Vanbelle (2008); Gantt (2000); Tiemersma (1987)-, a la Psiquiatría -Cfr. Godoy \& Bosi (2007)-, a la Educación-Cfr. Torralba (2001)-,...
} 
un sustrato hebreo latente o criptojudaísmo (Peñalver, 2008: 209), corroborando de ese modo la tesis defendida por Alberto Sucasas (2006).

Señalaremos la influencia de las tradiciones griega y hebrea en su aportación. De la tradición griega destacaremos únicamente a Platón y su Bien más allá del ser3, así como a Henri Bergson y su novedad como temporalidad. Cada una por separado consigue lo contrario de lo que pretende, es decir, ajustar al Otro definitivamente a la idea que tengamos de él. Dicho de otro modo, cada una de estas tradiciones por separado logra petrificar al Otro por medio del logos apofántico griego y la palabra profética judía. Por ello, contempla ambas tradiciones separadas, no supeditada la una a la otra y traduciendo la palabra profética al logos griego en su obra filosófica. Así, inspirándose en Platón, Lévinas señala el ir más allá del ser o el deseo. Mientras que inspirándose en Bergson, Lévinas señala la diacronía como temporalidad imprevisible del Otro que siempre me precede. Coordenadas espaciotemporales ambas (más allá del ser y diacronía) en las que ubica el autor una de las nociones más importante de toda su obra: la noción de rostro.

Por otra parte, y gracias a la sagaz crítica de Jacques Derrida en su artículo Violencia y Metafisica (1967), Lévinas pasa de contemplar la ontología contraria a la ética en Totalidad e Infinito, a considerarla auspiciada por la ética en De otro modo que ser o más allá de la esencia. Pese a que la crítica de Derrida fuera fundamental en la maduración del pensamiento levinasiano, éste ha padecido fluctuaciones a lo largo de su evolución. Una de las clasificaciones que más aceptación ha tenido entre los especialistas es la establecida por Jean Luc Marion ${ }^{4}$, que subdivide la trayectoria filosófica del autor a partir de tres rupturas: con la fenomenología, con la ontología y con la teología ontologizada. En un principio rompe con la fenomenología clásica, pese a que conserve de por vida el método fenomenológico o epojé, que, como veremos, consiste en remontar lo tematizado a su estado anterior, es decir, en criticar el prejuicio.

Para Lévinas la filosofía no sólo está constituida del aspecto griego, sino también del hebreo. De hecho, la originalidad de la propuesta levinasiana consiste en presentar ambos aspectos amalgamados, uno necesitado del otro, uno siempre dependiente del otro, sin que ninguno pueda supeditarse al otro. Contemplar únicamente el aspecto hebreo nos aboca a una ética individualista centrada en salvaguardar la irreductibilidad del Otro, mientras que centrarnos exclusivamente en el aspecto griego traería consigo una moral comunitarista universal y totalitaria que privilegia al Mismo5. De hecho, para Lévinas, cada uno de estos principios [hebreo y griego], abandonados a sí mismos, no activa más que lo contrario de lo que quiere garantizar (Lévinas, 2001c:111). Centrarnos únicamente en el amor al Otro que el

\footnotetext{
3 Cfr. Platón (La República, 509 b).

4 Cfr. Marion (1992), pp. 13-17.

5 Cfr. Lévinas (1997a), pp. 15-16; (1988), p. 14 y (1997b), pp. 49 y 60.
} 
aspecto hebreo promueve, deja de lado la justicia, mientras que considerar solamente la justicia que el aspecto griego contempla nos lleva a la utilización de aquel lenguaje de corte por el que lo humano del Otro acaba siendo ajustado a lo Mismo. Lévinas considera ambos aspectos imprescindibles, considerando que el amor al prójimo, propio del individualismo ético del judaísmo, instaura la justicia, propia del comunitarismo griego.

No obstante, ésta es una justicia ética diferente a la justicia ontológica de los griegos. Una justicia que, no obstante, exige también la caridad (Lévinas, 2001b: 277). Una justicia investida por la ética y que, por tanto, exige siempre ir más allá. Esta justicia ética, en lugar de ser vivida como un yugo padecido de la Ley, se vuelve deseo, deseo de hacer más de lo que ella manda (Lévinas, 2006c: 84). De ahí que tener la ética como primera filosofía nos aboque a ir siempre más allá del cumplimiento estricto y obediente de los principios éticos. Mientras que el principialismo ético nos insta al cumplimiento de tales pautas de conducta preestablecidas, la impactación de la vulnerabilidad del Otro que despierta la mía propia no sólo me impulsa a ir siempre más allá del cumplimiento de tales principios éticos, sino que instaura en mí aquella vigilancia que impedirá en adelante categorizar definitivamente al Otro.

A nuestro modo de ver, la sensibilidad a la que alude Lévinas consiste en aquella impactación de la vulnerabilidad del rostro del Otro que hace aflorar en nosotros la nuestra propia. Así, sentir prevoluntariamente la irreductibilidad de la singularidad del Otro por haber sido afectado corporalmente antes que cognitivamente, nos lleva a que, tras de cada categorización ontológica, procedamos a la descategorización: el conocimiento que adquirimos del Otro se vuelve ético cuando impedimos que este conocimiento sea seguro, perfecto, infalible y definitivo; cuando velamos por descategorizar al Otro tras de cada categorización. Sentirnos afectados por la irreductible vulnerabilidad del Otro que despierta la mía propia, nos lleva a dicha descategorización, a la crítica de cada categorización, a la actitud crítica y autocrítica de nuestro proceder. Sentir prevoluntariamente la irreductible vulnerabilidad y sufrimiento del Otro instaura una vigilancia en nosotros gracias a la cual decidimos salvaguardar su inconmensurable singularidad, su decisión autónoma. Así, mientras que la conciencia ontológica se caracteriza por no exigir la descategorización de lo categorizado, la conciencia ética se caracteriza porque el sujeto, debido a haber sido impactado por la vulnerabilidad del rostro del Otro y así haber sido despertado a la suya propia, es exigido a salvaguardar irreductible la singularidad del Otro como la sintiera prevoluntariamente durante la intrusión de aquel. La exigencia de mantenerse vigilante, alerta, evitando la categorización definitiva se debe a que el sujeto ético siente y sabe que el sufrimiento y vulnerabilidad expresado por el rostro escapan a la idea que él tenga de los mismos. Por ello, esta sensibilidad es la que inviste la vigilancia en el sujeto ético. 
De este modo, la predilección de Jerusalén por el Bien y la de Grecia por el Verdad se complementan. La sensibilidad preoriginaria, amor al prójimo o ética que caracteriza a la Biblia6, se compatibiliza con el amor al conocimiento de los griegos7. De hecho gracias a que amamos o somos sensibles a la irreductibilidad del Otro, podemos proceder a descategorizar lo categorizado. Jerusalén y Atenas se abrazan para mantenerse tensa y vigilantemente inseparables: es preciso añadir a la Biblia -que enseña la singularidad primera e inimitable, la unicidad 'asimiladora' de cada alma- los escritos griegos, expertos en especies y géneros (Lévinas, 2001b: 277). No hay que olvidar que los griegos han sido siempre muy considerados por los sabios judíos 8 . Para Lévinas, Europa es la Biblia de los griegos (Lévinas, 1991: 14)9, ella es la concreción donde las sabidurías teórica y bíblica hacen más que converger (Lévinas, 2006d: 149). Por todo ello, la propuesta levinasiana, lejos de ser exclusivamente amor a la verdad, amor a la sabiduría, resulta ser sabiduría del amor ${ }^{10}$. Una propuesta que lejos de aborrecer la Verdad, la ubica siempre al auspicio del Bien. Un Bien que ya Platón fue capaz de vislumbrarlo más allá del ser. No en vano, por ciertos rasgos, los griegos han sido capaces de ser 'biblicos'(Lévinas, 2006b: 198).

\section{Del hay al rostro: el insomnio como vigilancia del sujeto ético}

Consideramos que, para comprender mejor la noción de hay, resulta imprescindible señalar que ésta fue concebida cuando Lévinas se encontraba recluido en un campo de trabajo como prisionero de guerra ${ }^{11}$. El hay es una noción que, desde nuestro punto de vista, pudo inspirar la noción de rostro si tenemos en cuenta que ambas nociones provocan el insomnio en el sujeto que las padece. En sus primeras obras, este insomnio originado por el hay, impide dormir, descansar plácidamente al sujeto; mientras que, en obras posteriores, el insomnio es debido a que la vulnerabilidad del rostro conmueve nuestra entraña profunda, despertando nuestra sensibilidad y, con ella, nuestra vigilancia ante todo intento por nuestra parte de categorizar definitivamente al Otro. Comenzaremos por analizar la noción de hay de sus primeras obras, para evidenciar que el despertar del sujeto ético a la vulnerabilidad

\footnotetext{
6 Cfr. Lévinas (2000b), p. 97.

7 Cfr. Lévinas (1997a), p. 22; (2000b), p. 98; (1991), pp. 13 y 14; (2006b), pp. 198-199; (2001b), p. 251; (2004a), p. 344; (2006c), pp. 55 y 291 y (1988), pp. 156 y 176; Lévinas \& Kearney (1998), pp. 204-205; Derrida (1989), p. 209.

8 Cfr. Lévinas (2004a), pp. 33-34 y (2006c), pp. 55 y 74.

9 También Cfr. Lévinas (2009), pp. 95, 96 y 99 y (2006d), p. 149.

10 Cfr. Lévinas (2003), pp. 242-243; (1991), pp. 5 y 7; (2006d), pp. 145 y 151; (2001b), pp. 130, 227 y 268 y (1994), p. 219.

11 Cfr. Lévinas, (2000a), pp. 10-11 y Malka (2006), p. 76.
} 
al que aludirá en obras de madurez, tiene su antecesor conceptual en el insomnio al que se refiere en sus primeras obras.

La noción de hay pretende trasladarnos una exterioridad que no se encuentra en correlación con una interioridad. Es algo inconmensurable que no puedo someter, domesticar ni controlar por medio de la intervención de mi voluntad. El hay imposibilita la distinción entre exterior e interior ${ }^{12}$ debido a que difumina los contornos, borra los límites. El hay, por lo tanto, no es conceptualizable, no es observable, captable, apropiable 13 o asimilable por el Mismo. Por todo ello, no puede ser nombrado, representado a través de ningún concepto: no puede serle adherido un sustantivo a ese término 'hay' (Lévinas, 2000b: 44-45(5)). El hay es negación de todo lo mundano, de todo lo conceptualizable, de todo lo cosificable. Es negación innegable dado que absorbe hasta a su propia negación ${ }^{14}$. El hay se erige como imperio de la desconceptualización, de aquello que no es ya mundo (Lévinas, 2000a: 73-79), de la falta total de contornos, de la ausencia absoluta de límites ${ }^{15}$.

El hay es presencia de la ausencia (Lévinas, 2000a: 86) que no es un contenido puramente presente sino la atmósfera misma de la presencia (Lévinas, 2000a: 85). Ausencia que se me presenta, que se cierne sobre mí, que me tiene asido antes de que pueda decidirlo. Efectivamente, tal desencarnación de la realidad, tal desconceptualización de la realidad ${ }^{16}$, sume al sujeto -que todavía se encuentra sin constituirse como tal- en la más profunda despersonalización, en la más severa impersonalidad, en el culmen del anonimato, pero sobre todo, en el más obsesionante de los insomnios. La oscuridad de la noche funde hasta difuminar por completo los contornos, manteniéndonos en vigilia perpetua: el ser es el mal, no porque sea finito, sino porque carece de límites (Lévinas, 1993: 85-87) ${ }^{17}$. El hay nos arrastra a la extrema vigilancia, al insomnio extremo antes de constituirnos como sujetos, como entidades impersonales.

El hay nos sume en una pasividad de sujetos impersonales, todavía sin constituir, que nos mantiene exiliados, desterrados de toda tierra firme bajo el sol y, por ello, despiertos ante un hay que es pura imprevisibilidad, ausencia total de contornos. Es la oscuridad de una noche sin luna la que nos hace caminar atentos a los probables peligros que nos puedan acechar, aunque nada seamos capaces de vislumbrar. Todo son contornos difuminados, estelas ambiguas, fantasmas de las cosas que fueron a plena luz del día pero que vagan errantes como almas en pena en búsqueda del descanso eterno que nunca llegará. Todo son siluetas que se confunden entre

\footnotetext{
12 Cfr. Cfr. Lévinas (2000b), pp. 44-45 y (2000a), pp. 70, 77, 78 y 79.

13 Cfr. Lévinas (2001c), p. 49 y (2000a), p. 69.

14 Cfr. Lévinas (2000a), p. 86; (2000b), pp. 43-44; (2006e), pp. 204 y 288 y (2003), p. 46.

15 Cfr. Lévinas (2000a), p. 79.

16 Cfr. Lévinas (2001c), pp. 47, 48, 49 y 51.

17 También Cfr. Lévinas (2000a), p. 17.
} 
sí, siluetas sin terminar, sin de-terminar, que se dirigen a nuestra sensibilidad de sujetos pasivos no ontológicamente constituidos todavía y, por ello, pre-ontológicamente afectados, como sucediera con la afectación corporal antes que cognitiva que origina el rostro del Otro en el sujeto que lo recibe. La noche nos aboca a la vigilancia extrema por la incertidumbre que aquella nos genera: vigilancia impersonal (Lévinas, 2000a: 80-83), vigilia sin objeto (Lévinas, 1993: 84-85), vigilancia frente a lo que nunca podremos categorizar definitivamente porque siempre nos precede y excede.

El hay origina la subjetividad de una existencia sin existente ${ }^{18}$, uno sin sí-mismo (Lévinas, 1993: 85-87), que no puede poder sobre sí ni sobre nada. Se es, como siendo parte de un ser en general (Lévinas, 2006e: 70-71) ${ }^{19}$ que no tiene propietario ${ }^{20}$. Se es pero sin que el sujeto que es pueda poseerse a sí mismo. El hay hace que el sujeto siga siendo sin que pueda poseerse ni poseer nada, ya que carece de punto de partida (Lévinas, 1993: 85-87). Del mismo modo que el exilio prevoluntario que ocasiona la impactación del rostro del Otro en el sujeto que lo recibe. No en vano, si el sujeto no puede poseerse a sí mismo es porque no puede hacer pie sobre la tierra firme bajo el sol para poder apropiarse de las cosas que, por cierto, no tienen contorno dado que se encuentran desconceptualizadas. La imposibilidad de conceptualización nos da la medida de que el sujeto no se encuentra constituido, puesto que si lo estuviera, natural y espontáneamente, procedería a la conceptualización, al dominio apropiativo de la realidad mediante la categorización cognitiva de ésta. Efectivamente, el sujeto, gracias a la invasión del hay, no puede poder dado que es puro existir impersonal que se encuentra a expensas de un ser en general, en el que vive como impersonalidad anónima.

La invasión del hay origina la pasividad de aquella existencia que se deja llevar sin poder tomar las riendas de su vida: hay (il y a) -impersonalmente-como 'llue$v e$ 'o 'es de noche' (Lévinas, 2004a: 363)21. Como existir sin existente, el yo no coincide consigo mismo ${ }^{22}$, no se detiene ni se interrumpe ${ }^{23}$, sino que se falla constantemente en todo intento por su parte de erigirse sobre una posición segura, fundido en un silencio ruidoso, cuasi enjuiciador: el silencio terrorífico de los espacios infinitos es terrorífico (Lévinas, 2006e: 204) ${ }^{24}$. Tal es el trasfondo del $\mathrm{ser}^{25}$, tal es el vacio que deja la negación del ser (Lévinas, 2003: 46) que vuelve incesantemente del sordo y anónimo ruido del hay (Lévinas, 2003: 45). Vacío que deja el ser pero

\footnotetext{
18 Cfr. Lévinas (1993), pp. 85-87.

19 Cfr. Lévinas (2006e), pp. 91 y 214; (2000a), pp. 17 y 77 y (2005), pp. 100 y 126.

20 Cfr. Lévinas (2000a), pp. 86, 89 y 90.

21 También Cfr. Lévinas (1993), pp. 84-85; (2000b), pp. 43, 44-45(5) у (2000a), pp. 78-79.

22 Cfr. Lévinas (2006e), p. 162.

23 Cfr. Lévinas (2003), p. 244.

24 También Cfr. Lévinas (2000a), pp. 78-79; (2003), p. 244 y (2000b), pp. 44-45(5).

25 Cfr. Lévinas (2003), p. 259.
} 
que está lleno (Lévinas, 2000a: 10-11) del hay. El hay se escucha pero no es ruido identificable sino ruido desfenomenizado que me afecta en mi sensibilidad pasiva de sujeto no ontológicamente constituidos ${ }^{26}$. Ruido o sonido que caracteriza al silencio de la noche 27 .

Como lo venimos anticipando, el hay sume al yo -no podemos llamarlo sujeto porque todavía es existir impersonal28 - en una pasividad anterior a la creación (Lévinas, 2000b: 43-44), fundido en una noche que es ruido silencioso, silencio ruidoso que no es ni nada ni ser (Lévinas, 2000b: 43-44). El yo se encuentra fundido y confundido, absorbido y hasta ahogado en la noche de su propia existencia ${ }^{29}$, ya que la corriente anónima del ser invade, sumerge todo sujeto, persona o cosa (Lévinas, 2000a: 77). Así, el yo, como existencia sin existente, se encuentra siendo en el ser en general, siendo en medio de la más completa impersonalidad, bañado, sumergido y fundido en una existencia anónima en la que se con-funde sin poder diferenciar entre su contorno y el de las demás $\operatorname{cosas}^{30}$ porque en la noche del hay todo se encuentra des-encarnado, des-conceptualizado, negado hasta en su contradicción: la noche es la experiencia propia del 'hay'. Ya no hay 'esto' ni 'aquello'; no hay 'algo'. Pero esta universal ausencia es, a su vez, una presencia, una presencia absolutamente inevitable (Lévinas, 2000b: 44-45(5))31. El desvarío caótico, la confusión más radical, la desorientación por antonomasia es la experiencia del hay ${ }^{32}$. No decido existir, ya que el hecho de existir se me impone cuando no hay nada (Lévinas, 1993: 84-85), cuando todavía mi yo no se ha constituido como ente, como sujeto ontológico.

En definitiva, la noción de hay pretende trasladar la ausencia total de rumbo de un yo desorientado que vaga errante en la noche de su vida como existencia sin existente que no puede poseerse ni apropiarse de nada, dado que la realidad se presenta sin contornos, desencarnada, desconceptualizada, inmediata e imprevisible. Todo se encuentra bañado en el horror del hay como trasfondo o fondo del ser, como sombra del ser. El hay muestra pues la existencia sin existente de un yo impersonal, anónimo y despersonalizado debido a la sombra del ser en la que se encuentra sumido, vigilante ante cualquier imprevisibilidad, amenazado sin descanso posible, sin guarida que lo cobije, porque el hay es aquello que perdura aunque parezca que ya no quede nada. El hay es aquello que llena el vacío que deja la luz con la que el ser ilumina el mundo. El hay es la sombra del ser que llena las zonas que quedan en penumbra. El hay es lo inverso del foco iluminador del ser que, aún siendo, se man-

26 Cfr. Lévinas (1999), pp. 73-79.

27 Cfr. Lévinas (2000b), pp. 43-44.

28 Cfr. Lévinas (2000a), pp. 89-91.

29 Cfr. Lévinas (2000a), pp. 78-79.

30 Cfr. Lévinas (2000b), pp. 44-45(5); (1993), pp. 84-85 y (2000a), pp. 78, 79, 80-83.

31 También Cfr. Lévinas (2000a), pp. 78-79.

32 Cfr. Chalier (1995), pp. 35-36. 
tiene en la oscuridad. La noche del hay es vigilancia extrema inasumible, anterior a la voluntad del yo. La imprevisibilidad y la inmediatez incierta e insegura mantienen al yo en alerta perpetuamente, como si en la noche, la muerte le pisara los talones. Insomnio del que el yo no puede descansar, insomnio no neutralizable, no domeñable por el sueño que le sería posibilitado en una guarida segura, certera y firme. Tal es la pasividad inasumible en la que sume al yo el hay.

\section{Hay como antecesor conceptual de la noción del rostro}

Años más tarde a sus primeras publicaciones, Lévinas reconocerá que abandona la noción de hay pero que considera pertinente seguir manejando la noción de sombra del hay ${ }^{33}$. Una sombra del hay que contempla como modo de trasladar la amenaza que se ciernen sobre el sujeto, como peso que graba la alteridad soportada por una subjetividad que no la funda. (...) La subjetividad alcanza la pasividad sin asunción desde detrás del zumbido anónimo del 'hay' (Lévinas, 2003: 245). La pasividad de la subjetividad de la que nos hablaba Lévinas frente al hay ${ }^{34}$, perdura aunque, 34 años más tarde, se origine frente al rostro de la alteridad. La pasividad a la que sumía el hay al yo, es suscitada, desde De otro modo que ser o más allá de la esencia, por el rostro del Otro: el 'hay' es todo el peso que graba la alteridad soportada por una subjetividad que no la funda. (...) La subjetividad alcanza la pasividad sin asunción desde detrás del zumbido anónimo del hay (Lévinas, 2003: 245).

No obstante, y aunque no es nuestra intención analizar aquellas obras en las que se produce esta transformación - habida cuenta de que ésto excedería con creces nuestro propósito así como el marco de esta investigación-, sí que consideramos que antes que en Totalidad e Infinito, la noción de rostro es empleada en el artículo de 1951 ¿Es fundamental la ontología?35 con un lenguaje ontológico, aunque anticipando que la ética derroca definitivamente a la ontología: el rostro 'significa' de otro modo. (...) Lo humano sólo se ofrece a una relación que no es un poder (Lévinas, 2001b: 22-23). Es ésta la significación ética del rostro (Lévinas, 2001b: 21) a la que se refiere ya por aquel entonces Lévinas. En este artículo, la noción de rostro pone en evidencia que Lévinas, todavía a través del uso de un lenguaje profundamente ontologizado, comienza a intuir aquel reducto humano que resulta inexpugnable por la ontología. Una diferencia sustancial con obras anteriores en las que ni se aludía al rostro ni parecía existir más que la amenaza del hay en el sujeto ontológico: la relación con el otro no es, pues, ontología. Este vínculo con otro que no

33 Cfr. Lévinas (2000b), pp. 49-50.

34 Cfr. Lévinas (2001c), p. 47.

35 Cfr. Lévinas (2001b), pp. 13-23. 
se reduce a la representación del otro sino a su invocación (Lévinas, 2001b: 19). Un vínculo que Lévinas entenderá como relación que no totaliza a los términos de la misma o relación sin relación.

Para Lévinas hacer pie en el ser no zanja la amenaza del hay. Mientras el sujeto se yergue sobre el ser, la amenaza del hay se encuentra al acecho. De ahí la pretensión obsesiva del sujeto de mismificarlo todo, de arrastrar la realidad a la luz como sea, a toda costa. El sujeto ontológico todo lo cosifica, todo lo ajusta a la medida de su categorías cognitivas por la intencionalidad noético-noemática: yo sé, luego tengo el poder y el dominio sobre aquello que sé. La representación es otra modalidad que vuelve una y otra vez a hacer presente, a presentificar la realidad con tal de controlarla. No en vano, el presente es el tiempo del ser en el que éste ejerce su hegemonía. Un presente al que arrastra el pasado y el futuro por la retención y la protensión respectivamente para poder controlarlos. El hic et nunc son características del sujeto ontológico. Un sujeto que se encuentra atemorizado por el más que probable retorno del hay del más acá36 del entretiempo ${ }^{37}$, es decir, por el regreso de la inmanencia del porvenir (Lévinas, 2001c: 57) que es el hay. Es por ello que el sujeto ontológico se obceca en alumbrarlo todo con $s u$ luz, se obsesiona con apoderarse de cuanto le rodea. Busca seguridad, sujetarse y seguir sosteniéndose gracias a todo eso de lo que se apropia y que mismifica: yo soy yo a costa de lo/los demás, gracias a la mismificación de los cuales conservo mi identidad frente la indeterminación del hay que me acecha a cada instante y con los que me permito ser intolerante porque son de mi dominio apropiativo.

En desarrollos posteriores, Lévinas dejará de lado la noción de hay, aunque utilice la sombra del hay como sinónimo de la alteridad que el sujeto soporta a su pesar. El entretiempo del hay cae en desuso, como noción exclusivamente vinculada a su perspectiva estética. Pero, en su lugar, la amenaza intuida por el sujeto es producida en adelante por el rostro, situado en coordenadas temporo-espaciales como la diacronía y el más allá del ser, dando lugar a un sujeto obsesionado a su pesar y subjetivado en la más pasiva de las pasividades. Podría parecer que Lévinas se hubiera inspirado en la noción de hay a la hora de elaborar su noción de rostro, habida cuenta de su parecido. Un parecido con el rostro que Lévinas reconoce que puede llegar hasta su posible confusión con el trajín del 'hay' (Lévinas, 2001a: 103).

Del mismo modo que el hay, el rostro es exterioridad sin correlación con la interioridad, exterioridad insondable que amenaza y mantiene vigilante al sujeto. El hay, como el rostro, genera una pasividad tal en el sujeto que antecede a su propia voluntad, haciendo de ello algo inasumible ${ }^{38}$, anterior al saber del sujeto, a la decisión del sujeto. El hay, como el rostro, se presenta ausente, afectando al sujeto en

\footnotetext{
36 Cfr. Lévinas (2001c), pp. 56 y 59.

37 Cfr. Lévinas (2001c), pp. 56-63.

38 Cfr. Lévinas (2001c), p. 48.
} 
su sensibilidad antes que en su conciencia cognitiva, afectándolo corporalmente antes que cognitivamente, como conmoción de entrañas, como despertar a mi vulnerabilidad por su vulnerabilidad. El hay, como el rostro, se presenta a sí mismo por sí mismo, sin auxilio del sujeto que lo padece. El hay, como el rostro, se encuentra desfenomenizado, desmundanizado y es invisible, pero no por ello es la nada o el ser. El hay, como el rostro, es imprevisibilidad inmediata, inmediatez imprevisible que mantiene al sujeto en alerta perpetua. El hay, como el rostro, suscita inseguridad e incertidumbre en el sujeto. El hay, como el rostro, se mantiene al margen de la luz: el uno en la sombra del ser y el otro como invisibilidad que, incluso, puede llegar a deslumbrar, como exceso de luz que impide la visión. El hay, como el rostro, se escucha: el primero es ruido del silencio que no es la nada ni el ser y suscita mi vigilia; mientras que el segundo es primera palabra que provoca mi testimonio. El hay, como el rostro, es participación inasumible 39 y no apropiación 40 .

\section{Del hay al rostro: la epojé como método que va más allá de la fenomenología}

El parecido de ambas nociones resulta sorprendente. No obstante, resulta evidente que el hay se caracteriza por hallarse en el mismo plano temporo-espacial que el sujeto que lo padece ${ }^{41}$, mientras que el rostro siempre precede y excede al sujeto 42 . En todo eso ha tenido mucho que ver el lenguaje ontológico utilizado por Lévinas en obras como Totalidad e Infinito. Precisamente por hacer uso de tal lenguaje ontológico, a Levinas, en sus primeras obras de corte más fenomenológico, le costó salir del ser, trascender el ser. La hegemonía del ser era tal que resultaba complicado encontrar el vericueto por el que ir más allá del ser. Ya en De la existencia al existente tiene como objetivo trazar los cauces para arribar al Bien más allá del ser, siguiendo a Platón ${ }^{43}$. En cualquier caso, el uso del discurso ontológico a la hora de trasladar esta salida del ser, provocará que no pueda salir del plano temporal sincronizante del presente, propiamente ontológico.

Como anticipábamos, el tiempo del ser es el presente y exponer una propuesta de salida del ser yendo para ello más allá del ser con un discurso ontológico le costará una de las más ingeniosas críticas realizadas a su obra Totalidad e Infinito a

\footnotetext{
39 Cfr. Lévinas (2000a), pp. 57-58.

40 Cfr. Lévinas (2001c), pp. 48-49.

41 El murmullo incesante del 'hay' golpea con su absurdidad el yo trascendental activo, principiante, presente (Lévinas, 2003, 245).

42 Cfr. Lévinas (2006e), pp. 210, 228, 229, 235, 294, 295, 296, 299, 300, 301, 303, 305 y 307; (2003), pp. 135, 165, 167, 236, 265 y 267.

43 El rostro humano es exterior al mundo como el Bien de Platón, que se presenta en lo más allá del ser (epékeine tes ousías) como lugar del Bien (Lévinas, 2006e, 125).
} 
cargo de Derrida ${ }^{44}$. Abordar lo más allá del ser con lenguaje ontológico obliga a Lévinas a no poder salir del choque de voluntades enfrentadas que se provoca en el presente. La argucia levinasiana se pone en marcha y tras abandonar el lenguaje ontológico, plantea la diacronía como temporalidad del Otro que atraviesa el presente, que pasa sin que nada pueda hacer el sujeto para impedirlo. La diacronía es el intervalo de tiempo que se abre entre la pregunta del rostro y la respuesta del sujeto que lo recibe ${ }^{45}$. También podría ser, por tanto, un entretiempo que se abre para que el sujeto pueda hacer el Bien, pueda salir más allá del ser46. La ambigüedad de la diacronía hace que pueda ser también sincronizable ${ }^{47}$. De hecho, la diacronía existe al margen del presente -curiosamente como el entretiempo que se mantenía paralelo al tiempo de los vivos ${ }^{48-}$, y atravesando el presente, afectando al sujeto en su sensibilidad pre-ontológica ${ }^{49}$.

Esto provoca una diferencia sustancial. Por una parte, mientras que el hay, por encontrarse abordado por un lenguaje ontologizado, es ubicado por Lévinas en el más acá del entretiempo, como sombra del ser, gracias al abandono del tal lenguaje ontológico, Lévinas es capaz de trasladar una temporalidad al margen del ser, es decir, la diacronía o tiempo impredecible del Otro que siempre precede al afán sincronizador del sujeto ontológico. Por otra parte, mientras que el hay se dirige a una sensibilidad ontológica de una existencia sin existente, el rostro se dirige a una sensibilidad pre-ontológica de un sujeto que abandona su condición de ontológico por hacer pie sobre el ser para pasar a exiliarse del $\operatorname{ser}^{50}$. He aquí que Lévinas, para derrocar la hegemonía del presente del ser, decide plantear una temporalidad preontológica como la diacronía que se dirige antes a la sensibilidad del sujeto -que no puede dejar de responder ante el sufrimiento ajeno-, que a su conciencia cognitiva -aquella por la que el sujeto mismificaba la realidad manteniéndose consiguientemente indiferente frente a la misma-51. Su discurso profundamente ontologizado y por ello sincronizante impedía que Lévinas pudiera plantear la temporalidad diacrónica como tiempo imprevisible del Otro que siempre precede al afán sincronizante del sujeto ontológico que lo pueda recibir. Así, el rostro se ubica en el más allá de la diacronía como temporalidad preontológica, como tiempo para hacer el Bien que el rostro regala al sujeto que lo recibe.

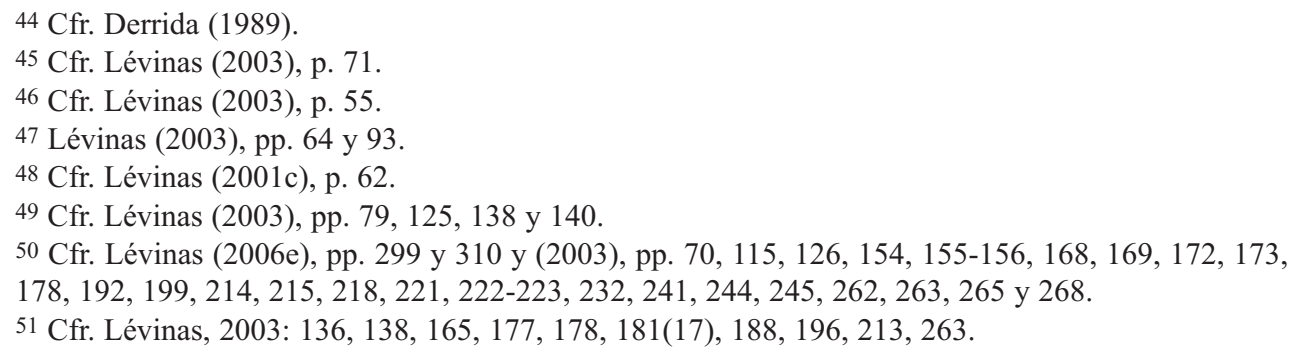


La comparación del rostro con la noción de hay nos resulta inevitable toda vez que hallamos rasgos comunes que fácilmente son identificables a lo largo de su obra. Probablemente el hecho de ir más allá de la fenomenología52, es decir, la utilización de la epojé como método para abordar tal preoriginariedad del rostro fuera el punto de inflexión. Evitar la constitución de la subjetividad trascendental por el saber, lleva a Lévinas a hacer uso de la epojé husserliana o reducción sin constitución ${ }^{53}$ por la que cuestiona el mundo natural y espontáneo. Sin este método fenomenológico, probablemente Lévinas habría sido incapaz de trascender el ser, de poder elaborar una fenomenología del rostro y trascenderla ${ }^{54}$, de descubrir aquella preoriginariedad que hace ser al ser. Gracias a la epojé, Lévinas somete toda ontología a crítica para devolverla a su preoriginariedad gracias a la ética, a sabiendas de que dejar a la ontología como primera filosofía no trae más que indiferencia, intolerancia y aniquilación de la singularidad del prójimo.

La categorización ontológica es imprescindible, dirá Levinas, pero jamás como primera filosofía. De ahí que, gracias a la epojé, Lévinas consiga remontarse a aquella preontología que da sentido humano y hace justa - o justifica- a la ontología 55 , devolviéndole al Otro su singularidad perdida en el proceso ontológico de categorización gracias a la crítica y la autocrítica del mismo. Así, la epojé es el método por el que se devuelve lo petrificado, lo solidificado a su estado preoriginario gracias a que el sujeto es cuestionado, criticado por el rostro del Otro. La epojé no sólo es el método utilizado por Lévinas para poder elaborar sus nociones, sino que es el método crítico al que se nos insta en la propuesta ética de Lévinas: la sensibilidad nos aboca a una actitud crítica y autocrítica para con el Otro que impide lo categoricemos definitivamente, promoviendo así un saber ético, descategorizador, que devuelve lo tematizado a su estado anterior, que remonta al Otro categorizado a su estado de vulnerabilidad cognitivamente irreductible.

\footnotetext{
52 Cfr. Lévinas (2003), p. 266.

53 Cfr. Gutiérrez (2009).

54 Entendiendo la noción de transcendencia como atravesamiento (trans) del Mismo por la mirada del rostro del Otro que provoca el arrepentimiento de un sujeto que no puede dejar de responderle al sentir y saber de la irreductible y singular vulnerabilidad humana de aquel, al que mira en adelante hacia arriba (scando), asumiendo la condición de extranjero frágil y vulnerable, situado siempre en posición de desventaja y llegando siempre tarde porque el rostro me precede y excede. Transcendencia del rostro como provocación prevoluntaria del arrepentimiento del Mismo como responsabilidad para el Otro, que mira hacia el cielo -cfr. Lévinas (1994), p. 195- porque aquél se sitúa en altura -cfr. Lévinas (2006e), p. 109.

55 Cfr. Lévinas (2006e), pp. 206, 227, 259, 304 y 306 y (2003), pp. 211, 230, 239, 240, 241, 247, 252 y 268 .
} 


\section{Epojé como antecesor conceptual de la vigilancia}

Lévinas fue aventajado alumno de Husserl, fundador de la fenomenología, sobre quien realizó una tesis doctoral que supuso la introducción de la fenomenología en Francia ${ }^{56}$. La impronta fenomenológica en Lévinas es indudable, especialmente en sus primeras obras. No obstante, el empleo de la fenomenología husserliana por parte de Lévinas no deja de ser particular. Husserl consideraba que para que se pudiera constituir la subjetividad trascendental se debía proceder poniendo entre paréntesis el mundo natural -a lo que denominó epojé- para posteriormente categorizar o abordar al Otro por el saber. A este proceder por el que únicamente se aborda al Otro por la razón exclusivamente, sin que el sujeto que lo recibe sea exigido a realizar la crítica del conocimiento adquirido que impediría la categorización definitiva de su irreductible singularidad, Lévinas lo denomina sensibilidad sin epojé57. Mientras que a aquel abordaje que procede sintiendo prevoluntariamente la vulnerabilidad del Otro por el que seguidamente, tras la categorización, promueve la descategorización del mismo por parte del sujeto que lo recibe, lo denomina sensibilidad con epojé58. Para Lévinas la epojé59 se efectúa gracias a la sensibilidad a la que somos despertados por el rostro del Otro. Una actitud crítica y autocrítica que se origina gracias a la intrusión del rostro del Otro, que cuestiona, critica mis injusticias cometidas como sujeto ontológico indiferente e intolerante para con él. La epojé posibilita el remonte del Dicho al Decir60, del fenómeno a lo que le hace ser fenómeno pero que es no-fenómeno y se encuentra desfenomenizado y es preoriginario.

Gracias a la súplica exigente del rostro del Otro por la que el sujeto se siente prevoluntariamente conminado a responder, a partir de este momento, éste se mantendrá exiliado del ser mientras se mantenga en extrema vigilancia61 ante todo intento por su parte de categorización definitiva del Otro tras cada operación ontológica de cálculo, medida y comparación. Es gracias a esta vigilancia extrema a la que el sujeto se siente abocado que practicará la epojé, la crítica sistemática, siempre atenta ante toda ontología que pretenda erigirse como origen del mundo. Por la epojé el Otro, tras la categorización ontológica, es nuevamente mirado al rostro devolviéndole su singularidad preoriginaria. Por la epojé toda categoría es remontada a aquello que le da sentido humano y que no se encuentra en el sujeto que habría categorizado, sino siempre más allá del ser y en diacronía, siempre más allá

\footnotetext{
56 Cfr. Lévinas (2004b).

57 Cfr. Lévinas (2003), pp. 129-130.

58 Cfr. Lévinas (2003), pp. 124 y 130.

59 Cfr. Lévinas (2003), pp. 59, 96, 124, 125 y 246.

60 Cfr. Lévinas (2003), pp. 59, 96, 108, 121, 125, 129, 230-231, 232, 235, 236 y 266.

61 Cfr. Lévinas (2003), pp. 66, 103, 104, 112, 156, 168, 180, 211, 219, 236, 244, 259, 264, 266 у 269.
} 
y antes del saber. Por la epojé se produce la reducción de la reducción del Otro al Mismo que se traduce en obsesión 62 del Mismo por el Otro: el Mismo obsesionado por el Otro al que no puede dejar de responder ante su sufrimiento.

Este más allá de la fenomenología63, este remontarse a lo más allá del ser, a lo más allá de la apariencia, de la fenomenalidad, se produce por la epojé como reducción sin constitución ${ }^{64}$. Es así como Lévinas evita la petrificación de la singularidad humana que no llega a constituirse en subjetividad trascendental, totalizante de su exclusiva singularidad -no en vano, según Lévinas, tal petrificación consiste en la adecuación a la forma impuesta por el Mismo que lleva al altericidio al alienar la exterioridad del Otro65. Este debe ser el método practicado por el sujeto ético exiliado del ser que, debido a la sensibilidad preoriginaria a la que es despertado por el rostro del Otro, se ve conminado a ejercer tal vigilancia extrema en aras de garantizar la singularidad y la libertad del Otro.

Sólo gracias a la epojé se es capaz de ir más allá de lo fenoménico, de toda modalidad de ontología que pasa a ser sistemáticamente cuestionada, sea en su modalidad de ley, de justicia, de política, etc. Cualquier modalidad de ontología es sometida a la crítica para ser devuelta a su situación preoriginaria. Este método es el modo como debe el sujeto ético ejercer su vigilancia extrema, recordando que la ontología adquiere su sentido humano y su justificación de la ética preoriginaria. Del mismo modo, la libertad del sujeto ético se encuentra investida desde dicha anterioridad pre-ontológica a la que debe ser pormenorizada y sistemáticamente devuelta. Es decir, la libertad no tiene origen en el sujeto, sino en su prójimo, que suscita su deseo irrefrenable de servirlo. En la ética levinasiana la responsabilidad precede a la libertad: de ahí que no pueda dejar de responder ante el padecimiento ajeno. Estar exiliado del ser es lo que hace que el sujeto se mantenga atento, alerta, cuestionando su libertad y reconociendo que es provocada por el Otro al que responde prevoluntariamente. La libertad es fruto del requerimiento que el Otro me hace frente al cual no puedo no responder.

Esta expresión -no puedo no responder- se debe a la siguiente afirmación de Lévinas: jincluso si adopta usted una actitud de indiferencia, usted está ya 'obligado' a adoptarla! El otro cuenta para usted, usted le contesta cuantas veces se dirija a usted, le concierne (Lévinas, 2009: 80). Afirmación que nos recuerda al axioma de la teoría de la comunicación de Paul Watzlawick en el que se aludía a que no hay no-conducta (....), es imposible 'no' comportarse. (...) Por mucho que uno lo intente, no puede dejar de comunicar. Actividad o inactividad, palabras o silencio,

\footnotetext{
62 Cfr. Lévinas (2006e), p. 226 y (2003), pp. 110, 135, 135(10), 145, 146, 148, 149(24), 150, 153, 155, $165,166,177$ y 195.

63 Cfr. Lévinas (2003), p. 266.

${ }^{64}$ Cfr. Gutiérrez (2009), p. 199.

65 Cfr. Lévinas (2006e), pp. 88-89.
} 
tienen siempre valor de mensaje (...). En sintesis (...): 'no es posible' no 'comunicarse' (Watzlawick, 1989: 50-52). Por tanto, frente al rostro del Otro el sujeto no puede no responder, siendo él y sólo él requerido para socorrerlo: el rostro le concierne a su pesar66. De este modo, la libertad es una libertad inspirada, una autonomía heteronomizada, una libertad investida que consiste en ser irreemplazable en el servicio al Otro ${ }^{67}$, sin que, en este proceso, sepamos ni cuándo ni dónde termina la llamada o solicitud del rostro del Otro, ni cuándo ni dónde comienza nuestra respuesta prevoluntaria. Tanto la llamada del rostro como la respuesta del sujeto, al producirse en diacronía, escapan a la lógica, a la imparable pretensión de acotar, de delimitar, de definir el comienzo y el final de ambos. Sea como fuere, el rostro me conmueve siempre antes de que mi conciencia cognitiva pueda intervenir.

Del mismo modo, y tras la irrupción del rostro, el sujeto se mantiene vigilante ante todo intento por su parte de categorizar definitivamente al Otro, por lo que el saber deja de ser ontológico. Es un saber que se encuentra siempre bajo sospecha y, por lo tanto, un saber ético que se produce gracias a la epojé. Por lo tanto, gracias a la epojé el sujeto transforma el saber ontológico en saber ético, velando por garantizar la singularidad humana sin totalizarla. El ser se humaniza cuando se reconoce deudor de la preoriginariedad ética. No obstante, ésta es una labor exclusiva del sujeto vigilante, exiliado del ser. Ésta es la labor del sujeto ético que deja de hacer pie en el ser, sintiéndose avergonzado ${ }^{68}$ de su libertad infinita y asesina de alteridades ${ }^{69}$. Sólo por esta ética como sensibilidad para con el Otro, el sujeto ético se mantendrá libre de la totalización a la que le obliga el ser sobre el que hacía pie y garantizará la singularidad y libertad del usuario. Sólo vigilante en su proceder ontológico de categorización del Otro y practicando la epojé será alumbrado como sujeto humano incapaz de no responder ante el dolor del Otro.

\section{Actitud crítica y autocrítica como vigilancia extrema frente al rostro del otro gracias a la epojé}

De entre las diferentes nociones que hemos venido utilizando, consideramos fundamentales el rostro del Otro y la responsabilidad. Nociones que son transversales a lo largo de toda su obra. El rostro lo entendemos como aquella vulnerabilidad del Otro que despierta la mía propia a modo de respuesta prevoluntaria a él. Es por ello que la responsabilidad la entendemos como ofrecimiento prevoluntario al Otro, como voluntad investida por la sensibilidad o como bondad que precede a la liber-

\footnotetext{
66 Cfr. Lévinas (2006e), pp. 111 y 226 y (2003), pp. 147, 148, 148(20), 152, 219 y 224.

67 Cfr. Lévinas (2006e), pp. 259 y 260 y (2003), pp. 106, 169, 183, 199, 210, 218 y 222.

68 Cfr. Lévinas (2006e), pp. 106, 107, 108, 109, 111, 217, 220, 226, 258, 298, 307 y 308.

69 Cfr. Lévinas (2006e), p. 106 y (2005), p. 251.
} 
tad. En palabras de Lévinas, ésta es una responsabilidad que desborda la libertad (Lévinas, 2006e: 102), que nos lleva más allá del ser, como deseo irrefrenable de ayudar al Otro. Así, el Otro, pese a ser inalcanzable por hallarse en las coordenadas espacio-temporales de la diacronía ${ }^{70}$ y de lo más allá del ser ${ }^{71}$, provoca mi sensibilidad y mi vigilancia.

La sensibilidad es una noción que comienza a ser desarrollada por Lévinas a partir de Totalidad e Infinito ${ }^{72}$, aunque más específica y profundamente en De otro modo que ser o más allá de la esencia 73 , mientras que las primeras huellas del término vigilancia las encontramos, a nuestro modo de ver, en sus primeras obras, cuando se refiere al insomnio ${ }^{74}$. Según reconoce el autor, yo he descrito la responsabilidad ética como insomnio o un mantenerse despierto, alerta precisamente porque implica un perpetuo deber de vigilar (...). El amor representa un incesante velar por el interés del otro (Lévinas \& Kearney, 1998: 214). Una sensibilidad75 que entendemos que consiste en la apertura prevoluntaria como expresión de mi vulnerabilidad tras la crítica, el juicio, la irrupción del rostro del Otro. Y una vigilancia 76 entendida como autocrítica exigida por esta sensibilidad que me lleva a descategorizar al Otro.

A la luz de tales nociones, pasamos a exponer la propuesta ética de Lévinas. Para este autor, el humanismo clásico se caracteriza porque la aproximación al Otro se realiza exclusivamente por la razón, porque se tiende a categorizar definitivamente al Otro, así como porque el sujeto ético tiende a intelectualizar los aspectos emocionales del Otro. Frente a esta perspectiva, Lévinas propone el humanismo del Otro, que fundamenta en nociones anteriormente señaladas como la sensibilidad y la vigilancia. Entendemos que la sensibilidad es una noción que tiene origen hebreo y que privilegia la conmoción de entrañas ${ }^{77}$, así como la vulnerabilidad, la irreductibilidad y la primacía del Otro. Para Lévinas, todo amor o todo odio del prójimo como actitud, refleja, supone una vulnerabilidad previa: misericordia, 'conmoción de entrañas'. Desde la 'sensibilidad', el sujeto es 'para el Otro': sustitución, responsabilidad, expiación (Lévinas, 2006a: 125).

\footnotetext{
70 Entendida como tiempo imprevisible del Otro que siempre me precede. Tiempo de lo contingente que no puedo anticipar y que, por ello, siempre se me escapa.

${ }^{71}$ Locus correspondiente a la temporalidad diacrónica. No-lugar que impide la fenomenalización totalitaria o categorización definitiva por parte del sujeto que recibe al Otro. Zona inexplorable y no conceptualizable por inalcanzable a la conciencia cognitiva del sujeto.

72 Cfr. Lévinas (2006e), pp. 201-207.

73 Cfr. Lévinas (2003), pp. 59-60, 117-162.

74 Cfr. Lévinas (2003), pp. 10 y ss.

75 Cfr. Lévinas (2003), pp. 59, 60, 79, 110, 120, 124,125, 131, 133, 134, 138, 140, 150, 198, 245, ...

76 Cfr. Lévinas (2003), pp. 66, 103, 104, 112, 156, 168, 180, 211, 219, 236, 244, 259, 264, 266, 269...

77 Expresión bíblica (Cfr. Jr 30,21) que Lévinas interpreta como afectación corpórea diacrónica no cognitivamente categorizable, no intelectualizable, es decir, irreductible al saber de la conciencia cognitiva -cfr. Lévinas (2003), pp. 59, 79, 109, 119, 121, $205 \ldots-$.
} 
Llegados a este punto, consideramos que la noción de vigilancia tiene tanto origen hebreo como griego. Tiene, en parte, origen hebreo puesto que privilegia la autocrítica que me lleva a la descategorización del Otro, siempre irreductible. Una autocrítica exigida por la sensibilidad preoriginaria que la inviste. Tiene, en parte, también origen griego porque consideramos que dicha noción de vigilancia toma probablemente como referente la epojé husserliana ${ }^{78}$, es decir, el método fenomenológico utilizado por Lévinas desde sus inicios, que nunca abandonará y que consiste en remontar lo tematizado a su estado anterior. Actitud que consiste en criticar el prejuicio o autocriticar nuestras propias intervenciones y que, como anticipábamos, comienza adquiriendo la forma y las características del insomnio en sus primeras obras. Así, el hecho de que la conciencia sea exigida a mantenerse vigilante, la diferencia de aquélla que no lo es. No en vano, la conciencia ética, es decir, aquella vigilancia investida por la sensibilidad, vela por descategorizar al Otro tras la categorización, mientras que la conciencia ontológica, como fijo estado de cosas que es (Lévinas \& Kearney, 1998: 214) no lo considera necesario, llegando así a reducir lo Otro a lo Mismo, es decir, a categorizarlo definitivamente.

Por todo ello, la propuesta ética de Lévinas aboga precisamente por ir siempre más allá del cumplimiento estricto de tales principios éticos, siendo críticos con el sufrimiento de cada caso concreto, así como autocríticos con nuestra propia intervención. Crítica y autocrítica que se traducen en términos levinasianos como vigilancia investida por la sensibilidad preoriginaria a la que somos despertados por el rostro del Otro. Si para Lévinas la ontología se encuentra investida por la ética, el principialismo ético u ontologismo deberá encontrarse, siguiendo a este autor, al auspicio de la ética.

\section{Conclusiones}

A nuestro modo de ver la epojé no sólo es el método empleado por Lévinas para elaborar su propuesta ética, sino que consiste en la actitud crítica y autocrítica que el sujeto ético concernido por el rostro de Otro se encuentra exigido a mantener para impedir categorizarlo a la medida de sus categorías cognitivas. La epojé es pues método fenomenológico que Lévinas nunca abandonará y actitud vigilante descategorizadora de lo ontológicamente categorizado. Gracias a la epojé, a la actitud crítica y autocrítica a la que somos exigidos tras sentir prevoluntariamente la vulnerabilidad irreductible del rostro del Otro, somos capaces de ir más allá del ser. Ir más allá del ser que consiste en que, partiendo de los principios éticos, los personalizamos en el caso concreto del Otro, velando por descategorizarlo tras la categoriza-

78 Cfr. Lévinas (2003), pp. 59, 96, 124, 125, 130 y 246. 
ción ontológica. Es decir, ayudamos al Otro a ayudarse a sí mismo sin categorizarlo definitivamente, protegiendo de ese modo su decisión autónoma.

Ir más allá del ser no deslegitima al sujeto ético mientras éste tenga la ética como primera filosofía, dado que así es como se encuentra tanto a la crítica (del rostro del Otro), como a la autocrítica (por medio de su propia vigilancia). En definitiva, ir más allá del ser establece la primacía del Otro, tendencia contraria al paternalismo ontológico, que supone para el sujeto ético, por una parte, acoger racionalmente sus aspectos emocionales sin categorizarlo definitivamente y por otra, un plus de responsabilidad. En el primer caso, en un principio, se siente al Otro, seguidamente, se sabe o se categoriza al Otro, para, finalmente, descategorizarlo. De ese modo, gracias a sentir prevoluntariamente la irreductibilidad de la singularidad del Otro, caemos en la cuenta de la urgencia de descategorizarlo, así como de la intolerancia e indiferencia para con el Otro que promueve la adquisición de un conocimiento ontológico, seguro e infalible de él. La vulnerabilidad irreductible del Otro, sentida prevoluntariamente, es la que me convence de que no puedo categorizarlo definitivamente y de que, tras categorizarlo, debo volver a mirarle nuevamente a su rostro irreductible. En el segundo caso, el plus de responsabilidad consiste en someter a crítica y autocrítica constante el conocimiento adquirido y nuestra intervención en todo momento.

En definitiva, ir más allá del ser consiste en tener la ética como primera filosofía. Gracias a tener la ética como primera filosofía, el sujeto ético es capaz de ir siempre más allá del ser, más allá del cumplimiento estricto y obediente de los principios éticos. De hecho, entendemos que ir más allá del ser consiste en que, partiendo de tales principios, el sujeto ético, gracias a la sensibilidad a la que ha sido despertado por el rostro del Otro, no sólo los personaliza en cada caso concreto sin categorizarlo definitivamente, protegiendo así su elección autónoma; sino que este sujeto ético, gracias a esta sensibilidad, siente en adelante la exigencia de mantener una actitud crítica -y por ello vigilante- con el sufrimiento del Otro, así como una actitud autocrítica constante para con su propia intervención. Por ello, nuestra propuesta pretende ser un complemento que amplía el alcance del principialismo ético a partir de las nociones de sensibilidad y vigilancia, que Lévinas propone gracias a la epojé, y que conjeturamos es, a la vez, método fenomenológico y noción que inspira el planteamiento de la vigilancia como actitud crítica y autocrítica del sujeto ético en la propuesta ética levinasiana.

\section{Referencias bibliográficas}

BAPTISTA, I. (2006): "Ethics and Social Intervention - for pedagogy of human proximity", Ponencia presentada en el seminario sobre Ética del Trabajo Social del Congreso Internacional de Trabajo Social, celebrado en la Vytautas Magnus 
University, Kaunas, Lituania, el 30 de Marzo de 2006. Recuperado el 25 de Octubre de 2009 de la Web de la autora: http://www.ibaptista.com/download/ kaunas2006.pdf.

Belli, LF. \& QuAdRelli, S. (2010): "La ética como filosofía primera: una fundamentación del cuidado médico desde la ética de la responsabilidad", Cuadernos de Bioética, 71, pp. 13-20. Recuperado el 10 de Noviembre de 2010 de http://www.aebioetica.org/rtf/01-BIOETICA-71.pdf.

Bello Reguera, G. (2008): "Hospitalidad, humanización y deshumanización. Dos lecturas recientes de Lévinas", en A. Alonso Martos (Ed.), Emmanuel Lévinas. La filosofia como ética, Valencia, Universitat de València, pp. 213-231.

BERNASCONI, R. (2009): "Lévinas y la trascendencia de la fecundidad", en P. Bonzi \& JJ. Fuentes (Eds.), El énfasis del infinito. Esbozos y perspectivas en torno al pensamiento de Emmanuel Lévinas, Barcelona, Anthropos, pp. 105-119.

DerRIDA, J. (1989): La Escritura y la Diferencia, Barcelona, Anthropos.

FERnÁNDEZ AGís, D. (2009): “Tiempo, política y hospitalidad. Una reflexión desde Derrida y Lévinas", Isegoria: Revista de Filosofia Moral y Política, 40, pp. 191-202.

Gabilondo, A. (2008): "Mi palabra suya", en A. Alonso Martos (Ed.), Emmanuel Lévinas. La filosofía como ética, Valencia, Universitat de València, pp. 275-288.

Galvin, KT. \& Todres, L. (2009): "Embodying Nursing Openheartedness: An Existential Perspective", Journal of Holistic Nursing, 27(2), pp. 141-149.

GANTT, E. (2000): "Levinas, psychotherapy and the ethics of suffering", Journal of Humanistic Psychology, 40(3), pp. 9-28.

GarcíA-BARO, M. (2007): La compasión y la catástrofe. Ensayos de pensamiento judio, Salamanca, Sígueme.

Godoy, Maa G. \& Bosi, Ma L. (2007): "A alteridade no discurso da Reforma Psiquiátrica brasileira face à ética radical de Lévinas", Physis: Revista de Saúde Coletiva, 17(2), pp. 289-299. Recuperado el 28 de Junio de 2008 de http://www.scielo.br/scielo.php?pid=S0103-73312007000200005\& script $=$ sci_arttext\&tlng $=$ g.

Gutiérrez, C. (2009): "Para una fenomenología de lo social en Emmanuel Lévinas", en P. Bonzi, P. y JJ. Fuentes (Eds.): El énfasis del infinito. Esbozos y perspectivas en torno al pensamiento de Emmanuel Lévinas, Barcelona, Anthropos, pp. 189-204.

HeLIN, K. \& LindSTRÖM, UA. (2003): "Sacrifice: an ethical dimension of caring that makes suffering meaningful", Nursing Ethics, 10(4), pp. 414-427.

IDARETA, F. (2010a): "Desde la Compasión de J. Addams a la Responsabilidad para con el Otro: La propuesta ética de E. Lévinas para el Trabajo Social", Portularia, 10(2), pp. 65-75.

IDARETA, F. (2010b): Ética como primera filosofia: aproximación de la ética de E. Lévinas al Trabajo Social, Saarbrücken, Editorial Académica Española. 
LÉvinAs, E. \& KEARnEy, R. (1998): “Ética del Infinito”, en R. Kearney, La paradoja europea, Barcelona, Tusquets, pp. 197-218.

Lévinas, E. \& Poirié, F. (2009): “Conversaciones”, en F. Poirié \& E. Lévinas, Ensayo y Conversaciones, Madrid, Arena, pp. 49-116.

LÉvinAs, E. (1982): "Notas sobre el pensamiento filosófico del Cardenal Wojtyla", Communia, 2, pp. 99-102.

LÉvinAs, E. (1988): A l'heure des nations, Paris, Minuit.

LÉvinas, E. (1991): "La ética”, en J. Casado \& P. Agudíez (Comps), El sujeto europeo, Madrid, Pablo Iglesias, pp. 3-15.

LÉvinas, E. (1993): El tiempo y el otro, Barcelona, Paidós.

LÉvinas, E. (1994): Dios, la muerte y el tiempo, Madrid, Cátedra.

LÉvinas, E. (1995): Altérité et transcendence, París, Fata Morgana.

LÉVINAS, E. (1996): Nouvelles lectures talmudiques, París, Minuit.

LÉVINAS, E. (1997a): Cuatro lecturas talmúdicas, Barcelona, Riopiedras.

LÉvinAs, E. (1997b): De lo sagrado a lo santo, Barcelona, Riopiedras.

LÉVINAS, E. (1999): De la evasión, Madrid, Arena.

LÉVINAS, E. (2000a): De la existencia al existente, Madrid, Arena.

LÉVINAS, E. (2000b): Ética e infinito, Madrid, A. Machado.

LÉvinAs, E. (2000c): La huella del Otro, México, Taurus.

LÉVINAS, E. (2000d): Sobre Maurice Blanchot, Madrid, Trotta.

LÉvinAs, E. (2001a): De Dios que viene a la idea, Madrid, Caparrós.

LÉVINAS, E. (2001b): Entre nosotros: ensayos para pensar en otro, Valencia, PreTextos.

LÉvINAS, E. (2001c): La realidad y su sombra: libertad y mandato, trascendencia y altura, Madrid, Trotta.

LÉvinAs, E. (2002): Fuera del sujeto, Madrid, Caparrós.

LÉvinAs, E. (2003): De otro modo que ser o más allá de la esencia, Salamanca, Sígueme.

LÉvinas, E. (2004a): Difícil libertad, Madrid, Caparrós.

LÉvinAS, E. (2004b): La teoría fenomenológica de la intuición, Salamanca, Sígueme.

LÉvinAS, E. (2005): Descubriendo la existencia con Husserl y Heidegger, Madrid, Síntesis.

LÉVINAS, E. (2006a): Humanismo del otro hombre, Madrid, Siglo XXI.

LÉvinAs, E. (2006b): Los imprevistos de la historia, Salamanca, Sígueme.

LÉvinAs, E. (2006c): Más allá del versículo, Buenos Aires, Lilmod.

LÉVINAS, E. (2006d): "Paz y Proximidad", Laguna, 18, pp. 143-151.

LÉvinAs, E. (2006e): Totalidad e Infinito: ensayo sobre la exterioridad, Salamanca, Sígueme.

LÉvinAS, E. (2006f): Trascendencia e inteligibilidad: seguido de una conversación, Madrid, Encuentro. 
LÉvinas, E. (2008): Nombres Propios, Madrid, Fundación Emmanuel Mounier.

LeVY-MALMBERG, R. \& ERIKSSON, K. (2010): "Legitimizing basic research by evaluating quality". Nursing Ethics, 17(1), pp. 107-116.

MARDONES, JM". (2004): "Sufrimiento humano y respuesta política", en F. Bárcena, C. Chalier, E. Lévinas, J. Lois, JMª Mardones \& J. Mayorga, La autoridad del sufrimiento. Silencio de Dios y preguntas del hombre, Barcelona, Anthropos, pp. 43-60.

MARION, JL. (1992): “Prólogo”, en G. González R. Arnáiz, E. Lévinas: Humanismo y Ética, Madrid, Cincel, pp. 11-17.

MÉLICH, JC. (2010): Ética de la compasión, Barcelona, Herder.

Nortvedt, P. (2001): "Clinical Sensitivity: The Inseparability of Ethical Perceptiveness and Clinical Knowledge", Research and Theory for Nursing Practice, 15(1), pp. 25-43.

PeÑalver, P. (2008): "Estructuras metódicas y temas metafísicos en la fenomenología de Emmanuel Lévinas", en A. Alonso Martos (Ed.), Emmanuel Lévinas. La filosofía como ética, Valencia, Universitat de València, pp. 199-211.

Platón (1988): La República, Madrid, Alianza.

Rossiter, A. (2011): "Unsettled social work: The challenge of levinass ethics", British Journal of Social Work, 41(5), pp. 980-995.

Rubilar, $\mathrm{M}^{\mathrm{a}} \mathrm{G}$. (2009): Alteridad y Trabajo Social. Perspectivas y alcances de la experiencia de alteridad en el Trabajo Social en contextos de exclusión, Tesis Doctoral, Universidad Pontificia Comillas, Madrid.

SuCASAS, A. (2006): Lévinas: lectura de un palimpsesto, Buenos Aires, Lilmod.

Tiemersma, D. (1987): "Ontology and ethics in the foundation of medicine and the relevance of Levina's view", Theoretical Medicine, 8(2), pp. 127-133.

TorralBA, F. (2001): "La llamada del otro vulnerable: hacia una fundamentación de las éticas profesionales", Educación social: Revista de intervención socioeducativa, 17, pp. 27-42.

VANBELLE, G. (2008): "In the beginning was a relationship", Revue belge de medecine dentaire, 63(2), pp. 77-80.

WATSON, J. (2003): "Love and caring. Ethics of face and hand - an invitation to return to the heart and soul of nursing and our deep humanity", Nursing Administration Quarterly, 3(27), pp. 197-202.

Watzlawick, P., Bavelas, JB. \& Jackson, DD. (1989): Teoría de la comunicación humana: interacciones, patología y paradojas, Barcelona, Herder.

Francisco Idareta Goldaracena

Universidad Pública de Navarra

fran_idareta@yahoo.es 